\title{
Haptic perception of partial-rod lengths with the rod held stationary or wielded
}

\author{
TIN-CHEUNG CHAN \\ The Chinese University of Hong Kong, Shatin, New Territories, Hong Kong
}

\begin{abstract}
Three experiments on the haptic perception of partial-rod lengths are reported. The rods were gripped between the two ends and held horizontal. The subjects held the rods stationary; the distribution of mass of the segment in front of the hand was fixed, while the distribution of mass of the segment behind the hand was varied. Perceived forward length was found to be significantly affected by the distribution of mass of the backward segment. Similar results were obtained when the rods were wielded. The results indicated that partial-rod lengths are specified by functions of mechanical perturbations acting on the hand, and not by the breaking up of the first moment of mass or the moment of inertia of the rod by attention as suggested previously by others. The results are also discussed with respect to invariant detection and attention.
\end{abstract}

It has been found that by holding or wielding a homogeneous rod gripped at one end, the length of the whole rod can be perceived without looking at it. When the rod, gripped at one end, is held stationary and horizontal, the perceived length of the whole rod depends on the rod's first moment of mass (the distribution of mass of the rod about a vertical axis through the wrist, hereafter called the first moment; see Appendix) (Hoisington, 1920). If the rod is wielded, the perceived length of the whole rod depends on another property of the rod, called the moment of inertia (inertia to rotation; also called the second moment, see Appendix) (Solomon \& Turvey, 1988).

A new question arises if we consider gripping the rod between the two ends. Could the segments forward and backward from the hand be perceived separately by means of attention? Burton and Turvey (1991) claimed that when a rod is gripped between its two ends and held stationary, the partial lengths of the rod forward and backward from the hand can be perceived accurately by attentionally splitting the first moment of the whole rod into two parts: forward and backward. Similarly, Solomon, Turvey, and Burton (1989) argued that when a rod is gripped between its two ends and wielded, partial lengths can be perceived accurately by attentionally splitting the moment of inertia of the whole rod. However, if the mechanical perturbation produced in holding or wielding a rod is examined, this argument of splitting either the first moment or the moment of inertia does not hold up.

This research was supported by the Shaw College Student Campus Work Scheme (fall 1991) and Direct Grant 220201070 of The Chinese University of Hong Kong. Emily Lai helped in running experiments. The author would like to thank M. T. Turvey, C. Fowler, and M. Bond for reading the first draft, and G. Gingham, L. E. Krueger, and two other anonymous reviewers for constructive criticism. Correspondence should be addressed to Tin-cheung Chan, Department of Psychology, The Chinese University of Hong Kong, Shatin, New Territories, Hong Kong (e-mail: tcchan@cuhk.hk).

\section{Mechanical Perturbation}

According to Gibson (1979), in order to understand visual perception one has first to know the properties of light so that the structure in the optical array can be revealed. Likewise, in order to understand haptic perception, one has to begin with the mechanical perturbations that set up the haptic array.

In holding a rod stationary, the weight of the rod, $\mathbf{W}$, which is proportional to its mass, $m$, acts downward. The mass is a property of the rod, whereas the weight is a mechanical perturbation that produces tissue deformation ( $\mathbf{W}=m \mathbf{g}$, where $\mathbf{g}$ is the acceleration due to gravity) ${ }^{1}$ Unless the rod is held at its center of mass, a turning tendency called static torque ( $\mathbf{N}_{\mathbf{s}}$; see Appendix), produced by the weight of the rod around the wrist, is also experienced ( $\mathbf{N}_{\mathrm{s}}=\mathbf{r \times m g}$, where $\mathbf{r}$ is the perpendicular distance from the center of mass of the rod to the vertical axis through the wrist as shown in Figure 1 , and $\mathbf{x}$ is a vector cross product ). Conversely, static torque equals the first moment $(\mathbf{M}=m \mathbf{r})$ of the rod multiplied by the acceleration due to gravity $\left(\mathbf{N}_{\mathbf{s}}=\mathbf{M x g}\right)$. The first moment is a measure of the distribution of the mass of the rod about the vertical axis through the point where it is pivoted. It is a property of the rod (Burton \& Turvey, 1991). As is shown in Figure 1, to keep the rod stationary, the hand has to balance $\mathbf{W}$ with an upward thrust, $-\mathbf{N}$, and $\mathbf{N}_{\mathbf{s}}$ with a counterclockwise torque, $-\mathbf{R}$.

In addition to overcoming the weight, $\mathbf{W}$, and static torque, $\mathbf{N}_{s}$, stated above, to rotate a rod with an angular acceleration $\dot{\omega}\left(\mathrm{rad} / \mathrm{sec}^{2}\right.$; there are $2 \pi$ radians in a circle), the hand has also to overcome an inertial torque, $-\mathbf{N}_{\mathbf{i}}$ (see Appendix), produced by the rod on the hand. This inertial torque on the driving hand is always in a direction opposite to that of acceleration (Figure 2). If rotation is limited on the plane of the paper, the inertial torque equals the moment of inertia, $I$, of the rod multiplied by the angular acceleration, $\dot{\omega} ;\left(\mathbf{N}_{\mathbf{i}}=I \dot{\omega}\right)$. By comparing the 


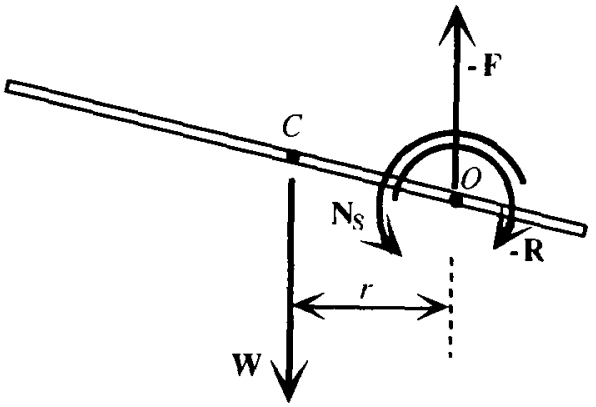

Figure 1. Free body diagram of a rod held stationary. $O$ is the wrist serving as the pivot point, $C$ is the center of mass of the rod, $W$ is the force exerted by the mass, $-F$ is the reactive force to $W$, $N_{s}$ is the static torque of the rod, and $-R$ is the reaction to $N_{s}$. For $N_{s}$ and $-R$, the directions indicate the sense of rotation, and are a schematic representation of torques into and out of the paper through $O$.

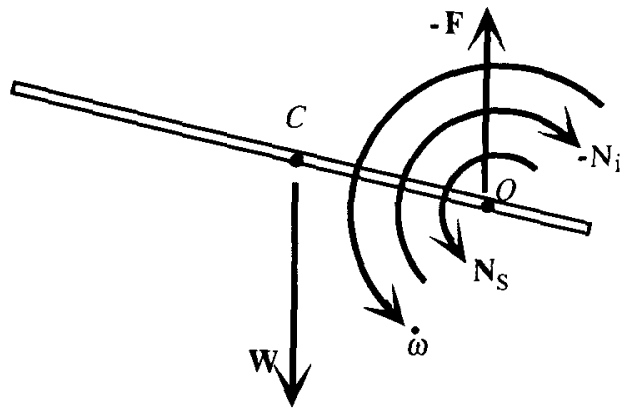

Figure 2. Static and inertial torques acting on the hand in wielding a rod in a clockwise direction. $O$ is the wrist serving as the pivot point, $-F$ is the reactive force to $W, \dot{\omega}$ is the acceleration of rotation, $-N_{i}$ is the inertial torque, and $N_{s}$ is the static torque. The muscular torque required to rotate the rod is $\left(\mathbf{N}_{\mathrm{i}}-\mathbf{N}_{\mathrm{s}}\right)$. If rotation is in a counterclockwise direction, the muscular torque required to rotate the rod is $-\left(N_{i}+N_{s}\right)$. The directions indicate the sense of rotation for torques perpendicular to the paper through $O$.

equation for angular motions to that of the translational motions (force $=m \mathbf{a}$, where $m$ is mass and $\mathbf{a}$ is acceleration), moment of inertia can be understood as the rotational mass. Just as mass is the inertia for translation, so moment of inertia is the inertia for rotation. It is a property of the rod, whereas inertial torque and angular acceleration are mechanical perturbations. To rotate a rod with an angular acceleration, the muscle is sensitive to the inertial torque. Joints, however, are sensitive to angular displacement, angular velocity, and angular acceleration. In the wielding of a rod, both inertial torque and angular acceleration vary. The greater the angular acceleration is, the larger the initial torque will be. Yet the ratio $\mathbf{N}_{\mathrm{i}} / \dot{\omega}$ is a constant corresponding to the moment of inertia.

The mass, the first moment, and the moment of inertia of a rod can each be regarded as the algebraic sum of their elementary components. The mass of a rod, $m$, is the sum of its elementary masses $\left(m=\Sigma m_{i}\right)$. For an elementary mass $m_{\mathrm{i}}$ at a perpendicular distance $\mathbf{r}_{\mathrm{i}}$ from a reference axis, its first moment is $m_{i} r_{i}$; the first moment of the rod is their algebraic sum $\left(m \mathbf{r}=\Sigma m_{\mathrm{i}} \mathbf{r}_{\mathrm{i}}\right)$. Similarly, in rotating a rod, the moment of inertia of each elementary mass $m_{\mathrm{i}}$ with a distance $r_{\mathrm{i}}$ from the point of rotation is $m_{\mathrm{i}} r_{\mathrm{i}}{ }^{2}$; the moment of inertia of the rod is their algebraic sum $\left(I=\Sigma m_{\mathrm{i}} r_{\mathrm{i}}^{2}\right)$.

The weight, the static torque, the inertial torque, and the angular acceleration are mechanical perturbations. Although they are produced in relation to the mass, the first moment, and the moment of inertia that are the properties of the rod, it is the various mechanical perturbations in combination that set up the haptic array.

\section{The Impossibility of Attentionally Splitting the Mass Distribution}

Burton and Turvey (1991) claimed that when a rod is held stationary at a position between the two ends, the perceived whole length is specified by the first moment of the whole rod pivoted at the wrist. The perceived partial length of the rod in front of the hand, however, depends only on the first moment of the forward segment of the rod. Their main assertion is that, for detection, the first moment of the forward segment can be split apart from that of the rest of the rod through attention. To support such an attentional split of the first moment of a rod, they showed that, so long as the distribution of mass of the forward segment stayed the same, the perceived forward length remained the same irrespective of attaching a mass to different locations on the backward segment. Similar results and arguments were offered by Solomon et al. (1989), who claimed that, in the wielding of a rod, the lengths of different segments were specified by the corresponding moments of inertia of rod lengths detected through selective attention.

Although supporting data were produced, such claims appear to be contradictory to the basic principles of mechanics. The resultant of any combination of forces acting on a rigid body at any point consists of one translational force and one rotational force only (Goldstein, 1980). It is impossible to split up either of these resultant forces into its constituent elements, for this would require an inverse operation of the algebraic summation of an uncountable number of forces, resulting in a solution with an infinite number of possibilities. It is true that in vector notation, a force can be decomposed into its components along the coordinate axes. This, however, is not the same as the inverse operation of the algebraic summation of forces, which is indeterminate. The perception or judgment of the whole or partial length has to depend only on the resultant weight, the resultant static torque, and the resultant inertial torque. In terms of the properties of the rod, the forward length can only be perceived with respect to the first moment or the moment of inertia of the whole rod.

Burton and Turvey (1991) were aware of the problem of this inverse operation but suggested that force struc- 
tures such as the gradient at the holding hand may give additional information for such partition. Yet partial perception of rod length through the detection of the force gradient acting on the hand would not be the same as splitting the first moment by attention. In view of the contradictions with the principles of mechanics posed by a split of the first moment or the moment of inertia through attention in both holding and wielding conditions, it is necessary to produce alternative explanations for the perception of partial-rod length.

\section{Formulation of Alternative Hypotheses}

To explore an alternative explanation of the perception of partial-rod length, let us identify the equations in the perception of both the whole and the partial lengths.

When a rod is held stationary. When one holds a rod at any position other than the center of mass, the static torque, $\mathbf{N}_{s}$, and the weight of the rod, $\mathbf{W}$, are the only mechanical perturbations that produce tissue deformation. Carello, Fitzpatrick, Domaniewicz, Chan, and Turvey (1992) found that, with rods gripped at the end and held stationary at different inclinations, perceived length correlated with the magnitude of the static torque. Because the magnitude of the static torque does not involve direction, it can be represented as the absolute value $\left|\mathbf{N}_{\mathrm{s}}\right|$. On the other hand, in the study by Burton and Turvey (1990), where the rod was held at the center of mass (the first moment goes to zero at this point), the subjects judged the length on the basis of the rod's weight. Any account of rod length would have to deal with the continuum of possible positions extending between these two. Perceived whole length of a rod should thus be expressed as a function of the magnitude of static torque, $\left|\mathbf{N}_{s}\right|$, and the weight of the rod, $\mathbf{W}$.

$$
\text { Perceived whole length }=f\left(\left|\mathbf{N}_{\mathrm{s}}\right|, \mathbf{W}\right) \text {. }
$$

Regarding the perception of a forward length of a rod held stationary, two speculations may be made. First, of the two perturbations at the wrist, $\mathbf{N}_{s}$ and $\mathbf{W}$, only $\mathbf{N}_{\mathrm{s}}$ covaries with the forward length. $\mathbf{N}_{\mathrm{s}}$ is different from $\left|\mathbf{N}_{\mathrm{s}}\right|$ in that it has direction. $\mathbf{W}$ does not covary with the forward length. An increase in the forward or backward length also increases weight. Thus, weight may be considered as a residual factor, $e$, in perceiving forward length.

$$
\text { Perceived forward length }=h\left(\mathbf{N}_{\mathrm{s}}, e\right) \text {. }
$$

Second, it is hypothesized that the forward length is not perceived independently of the whole length. The location of the grip as the ratio of whole length to forward length can be perceived. For example, if the rod is perceived to be gripped at the middle, perceived whole length is twice as long as perceived forward length, and the perceived length ratio of whole to forward length is 2 . Once the ratio is perceived, whole length can be translated to forward length. Let us call the objective length ratio $Q$ and the perceived length ratio $Q^{\prime}$.

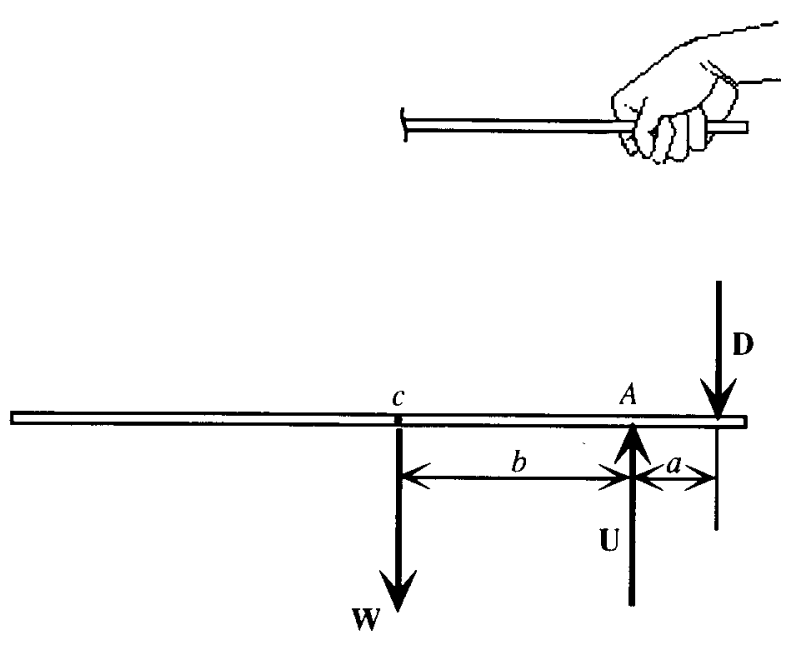

Figure 3. Free body diagram in which the weight of the rod is balanced by an upward force, $U$, and a downward force, $D$. $U$ is the reaction to the pressure of the rod on the middle phalanx of the index finger, whereas $D$ is the reaction to the kick of the rod on the heel of the hand. The style of gripping the rod is shown above.

Perceived forward length $=k$ (perceived whole length, $Q^{\prime}$ ), or, more precisely,

Perceived forward length $=$ Perceived whole length $/ Q^{\prime}$.

How can $Q^{\prime}$ be perceived? With a single rod held at different locations, the shorter the forward length is in relation to the whole length, the smaller will be the static torque, $\mathbf{N}_{s}$, but the greater will be the objective length ratio, $Q$. Perceived length ratio, $Q^{\prime}$, should therefore be inversely proportional to static torque. Yet when $Q^{\prime}$ is defined by static torque alone, it is impossible even to differentiate the $Q$ of a $100-\mathrm{cm}$ rod held horizontally at $70 \mathrm{~cm}$ of its length $(r=20 \mathrm{~cm})$ from that of a $200-\mathrm{cm} \operatorname{rod}$ of equal density held horizontally at $110 \mathrm{~cm}(r=10 \mathrm{~cm})$. Because the weight of the $200-\mathrm{cm}$ rod doubles that of the $100-\mathrm{cm}$ rod, the static torque $\left(\mathbf{N}_{\mathrm{s}}=\mathbf{r X W}\right)$ is the same for both rods. Yet the $Q$ s are different. To solve this problem, it is speculated that $Q^{\prime}$ can be specified by forces at more than one point on the hand.

Hoisington (1920) claimed that in holding a rod horizontal, there is a downward pressure on the index finger (the second phalanx) and an upward thrust (which he called 'kick") on the heel of the hand. The reactions on the index finger and the heel of the hand are shown as $\mathbf{U}$ and $\mathbf{D}$ on the rod in Figure 3 . This is the case when the rod is held at the rear end. When the rod is held at the front end, $\mathbf{U}$ and $\mathbf{D}$ switch locations on the hand. When the rod is held stationary, according to statics laws, the sum of vertical or horizontal forces should be zero. The sum of $\mathbf{N}_{\mathrm{s}}$ at any point should also be zero. 
If the sum of vertical forces equals zero,

$$
\mathbf{U}=\mathbf{D}+\mathbf{W} .
$$

If the sum of static torque at $A$ equals zero,

$$
a \mathbf{D}=b \mathbf{W} .
$$

From (4) and (5), we have

$$
\mathbf{U} / \mathbf{D}=1+a / b .
$$

Because $a$ is fixed (length of the palm), the ratio of $U / D$ depends on $b$. The ratio $\mathbf{U} / \mathbf{D}$ therefore specifies how close the grip is to the midpoint of the rod. Though this ratio is not useful in the percption of the length of the whole rod (Carello et al., 1992), it has a clear relationship with the location of the grip. Thus, $Q^{\prime}$ may be defined both by $\mathbf{N}_{\mathrm{s}}$ and by the ratio $\mathrm{U} / \mathrm{D}$.

When a rod is wielded. When a rod is rotated, the static torque is still present. The muscle torque required to rotate the rod equals the sum of the static and the inertial torques. With respect to Figure 2 , the static torque, $\mathbf{N}_{\mathrm{s}}$, produced by the weight always acts in an anticlockwise direction. The inertial torque, $\mathbf{N}_{\mathrm{i}}$, produced by rotation, however, depends on the direction of angular acceleration. With a counterclockwise acceleration, $-\mathbf{N}_{\mathrm{i}}$ is clockwise and the muscular torque required to rotate the rod is $\left(\mathbf{N}_{\mathbf{i}}-\mathbf{N}_{\mathrm{s}}\right)$. With a clockwise acceleration, $\mathbf{N}_{\mathrm{i}}$ is counterclockwise and the muscular torque required to rotate the $\operatorname{rod}$ is $-\left(\mathbf{N}_{\mathrm{i}}+\mathbf{N}_{\mathbf{s}}\right)$. Thus, in rotating a rod, the static torque may still be detected to specify partial lengths. The moment of inertia, however, is not sensitive to whether the forward or the backward length is longer.

If the preceding interpretation is indeed correct, then, whether the rod is held stationary or wielded, the perceived forward length should be affected by the static torque produced by the whole rod.

\section{EXPERIMENT 1 \\ Perceived Forward Length is Affected by the Distribution of Mass of the Whole Rod}

In the study by Burton and Turvey (1991) with rods of three different lengths and two gripping positions (at $1 / 2$ and $1 / 3$ of the length from the forward end), perceived forward lengths were compared between conditions when no mass was added and when a large mass was attached to the backward length of the rod. No difference in the perceived forward lengths was found between the two conditions. Thus it was argued that perceived forward length does not depend on the distribution of mass of the backward length. However, it is possible that, in those experiments, the effect of the distribution of mass of the backward length on the perceived forward length may have been masked by the more obvious effects of mass difference and gripping-position difference between trials.

In this experiment, a different setup was used. Instead of having three independent variables affecting perceived forward length, only one was used. Instead of simulating the change in rod length by using an attached mass to alter the distribution of mass of the backward length, the backward length itself was actually varied, with six rods of different lengths used. With the forward length kept constant at $35 \mathrm{~cm}$, only the backward lengths were varied among the six rods. When the backward segment was the shortest, the static torque was the largest. As the backward segment was increased, perceived forward length was expected to be reduced.

Although there was only one independent variable in this experiment, static torque and weight both changed with different rods. Such variation is similar to that in the study of Burton and Turvey (1991); the difference lies only in the source of the variation.

\section{Method}

Subjects. Ten undergraduates in an introductory psychology course at the Chinese University of Hong Kong participated in partial fulfillment of a course requirement.

Apparatus. Six hollow, homogeneous, thin steel rods (1 cm diam) of $40,50,60,70,80$, and $90 \mathrm{~cm}$ with respective masses of 34.81 , $43.4,51.35,58.8,67.8$, and $76.3 \mathrm{~g}$ were used. All rods were grasped at $35 \mathrm{~cm}$ from the front end. Two wooden boards $(1.5 \mathrm{~m}$ square) with a slit of $20 \mathrm{~cm}$ in between were used as screens to occlude the hand and the grasped rods. An armrest $0.8 \mathrm{~m}$ high was placed at the back of the slit. A piece of black cloth covered the top part of the slit (Figure 4). For subjects reporting length, a sliding red marker connected with a string was mounted on a board. By pulling the string up or down at the starting edge of the board, one could move the red marker along a meter rule fixed at the top of the board. The perceived length of a rod could then be translated to the distance of the marker from the starting edge. This length measurer was placed along the occluding board in front of the subject.

Procedure. The subjects positioned their right arm on the armrest, with their right hand behind the screens. Rods were placed by the experimenter into their right hand and were always gripped by the subjects at a location $35 \mathrm{~cm}$ from the front end. The subjects gripped the rods firmly, with the thumb positioned over the index finger (see Figure 3). This grip ensured that the subjects could not move the rod with the thumb independently of the wrist motion, so that the wrist would act as the pivot point of the rod-hand system. The subjects were told to hold the rod still, and that any slight movement would ruin the experiment. The experimenter held onto the rod until the subjects kept it horizontal and showed no downward tilting tendency. This precaution was particularly necessary when the rods were longer and heavier, although the use of light rods had already reduced the problem substantially. In each trial, the subjects moved the red marker away from themselves with their left hand to indicate the perceived forward length of the rod held in their right hand. They were encouraged to take as much time as was necessary for them to perceive the rod length accurately. At the end of each trial, the rod was taken away and the subjects moved the red marker back to the starting edge.

Before the experimental trials, the subjects were given several practice trials with a rod that was not used in the experiment. Special precautions were taken to check that the subjects did hold the rod still, but slight trembling was disregarded. It was found that the instruction to hold the rod still, together with the use of an armrest, was sufficient to halt all movement.

In the experiment, the six rods were presented randomly in each block of trials. There were eight blocks of 6 trials, with a total of 48 trials. There were two types of reports: forward length, and perceived length ratio, $Q^{\prime}$. Half of the subjects reported forward length in the middle four blocks of trials and $Q^{\prime}$ in the other blocks. The other half made their reports in the opposite order. When report- 


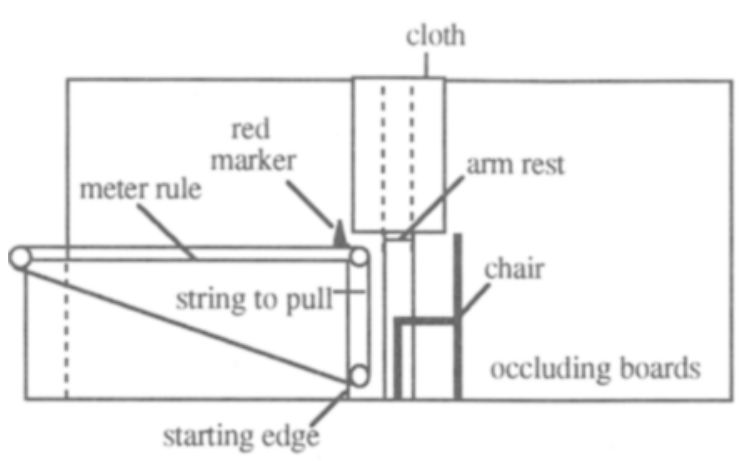

(A)

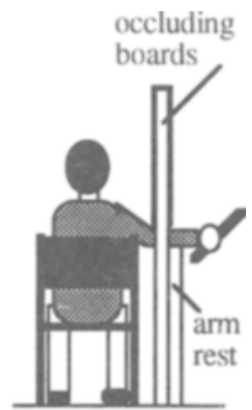

(B)

Figure 4. Apparatus. (A) Arrangement of the apparatus. (B) A subject holding a rod horizontal, with the right arm inserted into the slot between the two occluding boards. The view of the length measurer as shown in (A) is blocked from the subject.

ing length ratios, the subjects judged the whole length as so many times as long as the forward length.

Design and Prediction. There was only one independent variable (rod length), with six levels. The perceived forward length and the perceived length ratio, $Q^{\prime}$, were measured.

The claim that the perceived forward length is affected by the distribution of mass of the whole rod will be verified if the same forward length is perceived to be different when the backward length is varied. A stronger claim can be made by showing that the perceived forward length is affected by $\mathbf{N}_{s}$ (Equation 2). To show that $Q^{\prime}$ is actually perceived and is inversely proportional to $\mathbf{N}_{\mathbf{s}}$, a significant correlation between $Q^{\prime}$ and $\mathbf{N}_{\mathrm{s}}$ is needed.

\section{Results and Discussion}

The means of the perceived forward length and of $Q^{\prime}$ are listed in Table 1. An analysis of variance (ANOVA) showed that the effect of rod length was significant $[F(5,45)=20.3, p<.0001]$. A post hoc test (Tukey) showed that the perceived forward length changed when the backward length was varied between 5,35 , and $55 \mathrm{~cm}$ $(p=.01)$. The results showed that the perceived forward length varied although the actual forward length was fixed. The perceived forward length is therefore not a measure of the first moment of the forward portion of a rod. Estimates fell as backward length increased. When the per- ceived forward length was regressed on the static torque, a significant linear relationship was found; the static torque accounted for $98 \%$ of the variance, indicating that the perceived forward length is a function of the static torque of the whole rod (Figure 5). When $Q^{\prime}$ was regressed on $\mathbf{N}_{s}$, a significant linear relationship was found which accounted for $97 \%$ of the variance, showing that $Q^{\prime}$ can be determined from the static torque, $N_{\mathrm{s}}$ (Figure 6). ${ }^{2}$ Thus, in this experiment, the results indicated clearly that the forward length was not perceived independently of the distribution of mass of the backward length; rather, its perception is closely related to the static torque, $\mathbf{N}_{\mathrm{s}}$, and the perceived length ratio, $Q^{\prime}$.

That the perceived whole length is affected by the magnitude of static torque, $\left|\mathbf{N}_{s}\right|$, and the weight, $\mathbf{W}$, can be observed from the calculated perceived whole length in Table 1 . When backward length was increased from 5 to $35 \mathrm{~cm}$, while $\left|\mathbf{N}_{\mathrm{s}}\right|$ was reduced and $\mathbf{W}$ was increased, there was a slight but significant increase in perceived whole length. A reduction of $\left|\mathbf{N}_{s}\right|$ should lead to a decrease in perceived whole length. The slight increase in the results can only be attributed to the increase of weight. With backward length increased from 35 to $45 \mathrm{~cm}$, there was an abrupt increase in perceived whole length as a result of increase of both $\left|\mathbf{N}_{\mathbf{s}}\right|$ and $\mathbf{W}$.

Table 1

Mean Perceived Forward Length and Whole-to-Forward Length Ratio With Different Mass Distribution in Experiment 1

\begin{tabular}{ccccccc}
\hline $\begin{array}{c}\text { Rod } \\
\text { Length } \\
(\mathrm{m})\end{array}$ & $\begin{array}{c}\text { Backward } \\
\text { Length } \\
(\mathrm{m})\end{array}$ & $\begin{array}{c}\text { Static } \\
\text { Torque } \\
\mathbf{N}_{\mathrm{s}}(\mathrm{N} \cdot \mathrm{m})\end{array}$ & $\begin{array}{c}\text { Objective } \\
\text { Length } \\
\text { Ratio } Q\end{array}$ & $\begin{array}{c}\text { Perceived } \\
\text { Length } \\
\text { Ratio } Q^{\prime}\end{array}$ & $\begin{array}{c}\text { Perceived } \\
\text { Forward } \\
\text { Length }(\mathrm{m})\end{array}$ & $\begin{array}{c}\text { Calculated } \\
\text { Whole } \\
\text { Length (m) }\end{array}$ \\
\hline $\mathbf{0 . 4}$ & 0.05 & $\mathbf{0 . 0 5 1}$ & 1.14 & 1.40 & 0.213 & 0.298 \\
0.5 & 0.15 & 0.043 & 1.42 & 1.46 & 0.215 & 0.314 \\
0.6 & 0.25 & 0.025 & 1.71 & 1.63 & 0.190 & 0.310 \\
0.7 & 0.35 & 0.000 & 2.00 & 1.96 & 0.163 & 0.319 \\
0.8 & 0.45 & -0.033 & 2.29 & 2.83 & 0.136 & 0.384 \\
0.9 & 0.55 & -0.075 & 2.57 & 3.81 & 0.109 & 0.414 \\
\hline
\end{tabular}

Note-Forward length $=35 \mathrm{~cm}$ throughout. 


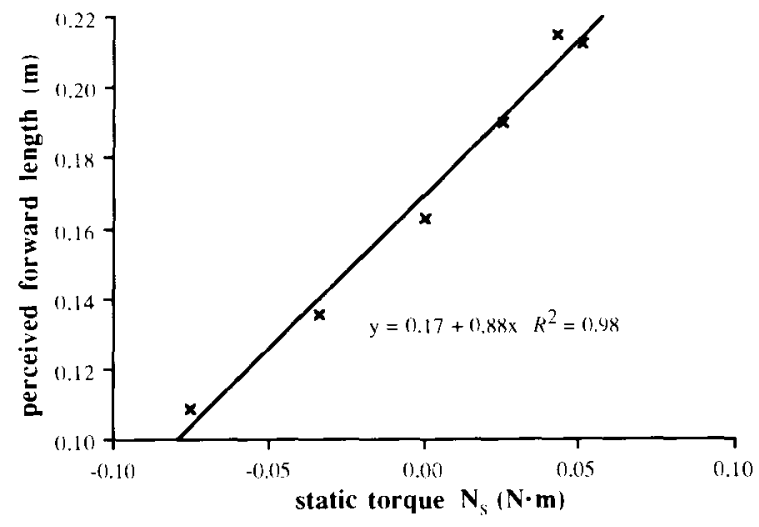

Figure 5. The perceived forward length is a function of the static torque, $\mathrm{N}_{\mathrm{s}}$ of the whole rod (Experiment 1).

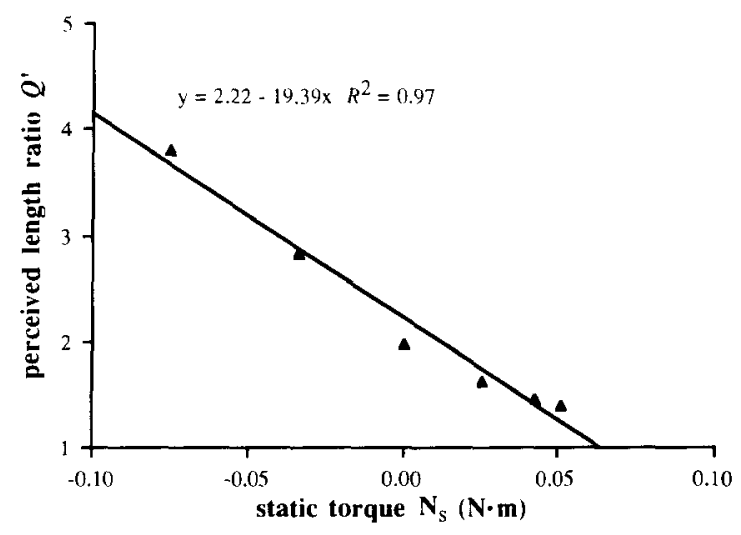

Figure 6. The perceived length ratio, $Q^{\prime}$, can be determined from the static torque, $\mathbf{N}_{\mathbf{s}}$ (Experiment 1).

\section{EXPERIMENT 2 \\ Extension of Experiment 1 with Mass Attachment and Without Reporting Ratio}

After reading the results of Experiment 1, M. Turvey (personal communication, August 1992) suggested to me that the reporting of ratio by subjects may affect their judgment of length. Moreover, he pointed out that in the many experiments he had conducted with a mass attached to a rod, he had not come across results similar to mine. Experiment 2 was conducted in response to his comments. It was expected that, if the effect in Experiment 1 was genuine, such an effect with length variation should be replicable with the mass-attachment variation used by Burton and Turvey (1991). Only one independent variable was used so that the effect of the distribution of mass of the backward length on perceived forward length would not be masked by other manipulations. A rod with a mass attached to both the forward and the backward length was grasped in the middle. The location of the mass attached to the backward length was varied. The perceived for- ward length was expected to change without the simultaneous reporting of ratios as the distribution of mass of the backward segment was varied.

\section{Method}

Subjects. Ten undergraduates in an introductory psychology course at the Chinese University of Hong Kong participated in partial fulfillment of a course requirement.

Apparatus. A thin, hollow steel rod $110 \mathrm{~cm}$ long $(1 \mathrm{~cm}$ diam, $115.4 \mathrm{~g}$ in mass) was held in the middle. A metal cylinder $(89.1 \mathrm{~g}$ in mass) was attached to the forward length $23 \mathrm{~cm}$ from the midpoint to produce a counterclockwise static torque. A metal disk (61.3 $\mathrm{g}$ in mass) was attached at $10,15,20,25,30,35,40,45$, 50 , or $55 \mathrm{~cm}$ back from the midpoint to counteract the static torque produced by the metal cylinder. As the metal disk was shifted from $10 \mathrm{~cm}$ toward $55 \mathrm{~cm}$, the resultant static torque reduced in magniude and then changed direction. The occluding screen and the length measurer were the same as in Experiment 1.

Procedure. The procedure was the same as in Experiment 1, with the following exceptions. The subjects gripped the rods in the middle, with forward length equal to backward length (but with the same gripping style shown in Figure 3). The 10 configurations with the metal disk attached to different positions were presented randomly to each subject in each block of trials. There were four blocks of trials, making a total of 40 trials. The subjects reported the forward length only, using the length measurer.

Design and Prediction. There was only one independent variable (location of attachment), with 10 levels. It was expected that the perceived forward length would change (decrease) as the metal disk on the backward length was shifted toward the back end.

\section{Results and Discussion}

The means of perceived forward length are listed in Table 2. An ANOVA showed that the location of attachment at the backward segment affected the perceived forward length $[F(9,72)=47.97, p<.0001]$. The fixed forward length was perceived as shorter when the metal disk was attached closer to the rear end. When perceived forward length was regressed on static torque, a significant linear relationship that accounted for $99 \%$ of the variance was found (Figure 7). The results confirmed that the perceived forward length was affected by the distribution of mass of the backward segment. In light of the results obtained, the reporting of ratio in Experiment 1 did not affect the report of length.

In this experiment, $\mathbf{W}$ was held constant. Shifting the location of the attached metal disk produced a change in

Table 2

Mean Perceived Forward Length as a Function of the Mass Distribution of the Whole Rod in Experiment 2

\begin{tabular}{ccc}
\hline $\begin{array}{c}\text { Location of Disk } \\
\text { Behind Midpoint }(\mathrm{m})\end{array}$ & $\begin{array}{c}\text { Static Torque } \\
\mathbf{N}_{\mathrm{s}}(\mathbf{N} \cdot \mathrm{m})\end{array}$ & $\begin{array}{c}\text { Perceived } \\
\text { Forward Length }(\mathrm{m})\end{array}$ \\
\hline 0.10 & 0.0141 & 0.469 \\
0.15 & 0.0111 & 0.419 \\
0.20 & 0.0081 & 0.406 \\
0.25 & 0.0051 & 0.375 \\
0.30 & 0.0021 & 0.344 \\
0.30 & -0.0009 & 0.316 \\
0.40 & -0.0040 & 0.282 \\
0.45 & -0.0070 & 0.249 \\
0.50 & -0.1000 & 0.227 \\
0.55 & -0.1300 & 0.209 \\
\hline
\end{tabular}




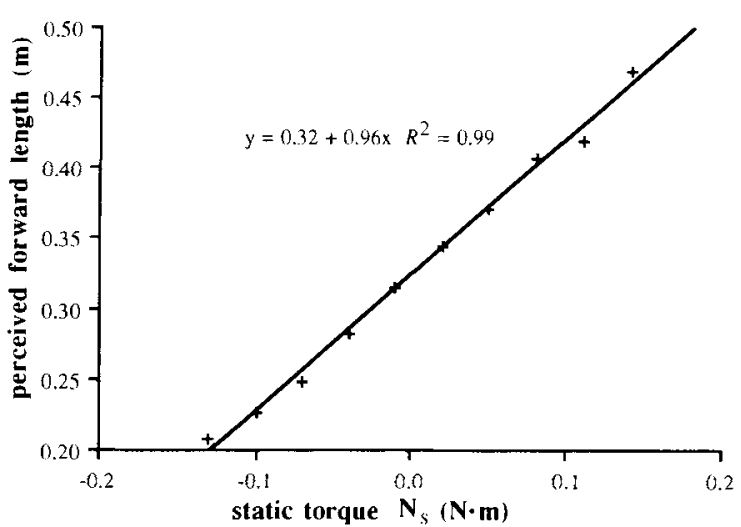

Figure 7. The perceived forward length is perfectly proportional to the static torque, $N_{s}$, when the weight of the rod is kept constant (Experiment 2).

force structure at the wrist similar to that produced by holding the rod at different positions. The perceived forward length was nearly perfectly predicted by the static torque, $\mathbf{N}_{\mathrm{s}}$, of the whole $\operatorname{rod}\left(R^{2}=.99\right)$.

\section{EXPERIMENT 3 \\ Perception of Partial-Rod Lengths by Wielding}

The argument that the perception of partial-rod lengths cannot be a result of attentionally splitting the first moment can be extended to the moment of inertia in the wielding of a rod. Solomon and Turvey (1988) showed that moment of inertia is the predictor of the perceived length of a wielded rod. This has been supported in other research (e.g., Chan \& Turvey, 1991). Yet Solomon et al. (1989) further claimed that the moment of inertia of the forward portion of the rod can be detected separately from that of the rest of the rod. They managed to show that with the forward length of the rods kept constant, the perception of the forward length was unchanged irrespective of the variation of distribution of mass at the backward part of the rods. Such splitting up of the moment of inertia is impossible because, as with the case of $\mathbf{N}_{s}$ when a rod is held stationary, the resultant inertial torque, $\mathbf{N}_{\mathbf{i}}$, in wielding a rod cannot be decomposed, nor can the moment of inertia, $I$, of the whole rod. Only the $I$ of the whole rod can be detected as a function of $\mathbf{N}_{\mathbf{i}}$ and angular acceleration, $\dot{\omega}$. The $I$ of a partial-rod length cannot be detected.

In this experiment, as in the study of Solomon et al. (1989), the subjects judged the length of an occluded rod by wielding it. A mass was sometimes attached to the forward or the backward length of the rod. It was expected that when the mass was added to the backward length, the perceived forward length would be shortened.

\section{Method}

Subjects. Eight undergraduates in an introductory psychology course at the Chinese University of Hong Kong participated in partial fulfillment of a course requirement.
Apparatus. Two hollow aluminum rods (1 $\mathrm{cm}$ diam), one long $(80 \mathrm{~cm}, 67.8 \mathrm{~g})$ and one short $(50 \mathrm{~cm}, 46.7 \mathrm{~g})$, were used, along with a cylindrical mass $(1 \mathrm{~cm}$ internal diam, $3 \mathrm{~cm}$ external diam, $1.25 \mathrm{~cm}$ long, $64.4 \mathrm{~g}$ ) that was attached to the two rods by tightening a built-in screw. Both rods were gripped in the middle. There were five configurations for mass attachment: front end, front, no attachment, back, back end. On the short rod, the mass was attached at 18.57 or $0.62 \mathrm{~cm}$ from either the front end or the rear end; on the long rod, the mass was attached at 33.87 or $0.62 \mathrm{~cm}$ from either end. The same occluding screens and length measurer were used as in Experiment 1.

Procedure. The procedure was the same as in Experiment 1, with the following exceptions. All rods were grasped in the middle (with the thumb positioned over the first finger so that the wrist acted as the pivot point when wielded, as shown in Figure 3). The subjects were instructed to swing the rods up and down slowly to perceive the lengths. The perceived whole length and the perceived forward length were reported by adjusting the distance of the red marker from the starting edge. The 10 rod configurations were presented randomly in each block of trials. There were eight blocks of trials, with a total of 80 trials. Two types of dependent variables were measured: perceived lengths (forward length and whole length), and perceived length ratio, $Q^{\prime}$. Half of the subjects reported perceived lengths in the middle four blocks of trials and $Q^{\prime}$ in the other blocks; the other half made their reports in the opposite order.

Design and Prediction. This was a $2 \times 5$ within-subject design, with two levels of rod length and five levels of configuration, the latter in ordinal scale. The perceived forward length, the perceived whole length, and the perceived length ratio, $Q^{\prime}$, were recorded. It was expected that perceived forward length would be shorter when a mass was attached to the backward length. Moreover, contrary to the claim of Solomon et al. (1989), moment of inertia, $I$, is not sensitive to whether the forward length or the backward length is longer, and thus $I$ should not be useful in partial-length judgment. It was expected that the perceived length ratio and the forward length would be correlated with the static torque of the rod, while only the perceived whole length would be correlated with the moment of inertia of the rod.

\section{Results and Discussion}

The means of the perceived lengths and the perceived length ratio, $Q^{\prime}$, are tabulated in Table 3 . An overall ANOVA showed that the effect of rod length was significant $[F(1,7)=99.20, p<.0001]$, that the effect of configuration was significant $[F(4,28)=58.70, p<.0001]$, and that the interaction between rod length and configuration was significant $[F(4,28)=10.84, p<.0001]$. The objective of this experiment, however, concerned the shortening of the perceived forward length when a mass was attached to the backward length. Planned comparisons (Keppel, 1991) were conducted on perceived forward length between the conditions of no attachment and attachment at the backward length in each of the two rods. A significant difference was found in both cases $[F(1,7)=$ $34.33, p<.001$ for the $80-\mathrm{cm} \operatorname{rod} ; F(1,7)=12.0, p<$ .025 for the $50-\mathrm{cm}$ rod]. The results showed that in wielding, perceived forward length is affected by the distribution of mass of the backward length. The notion that forward length is perceived by attentionally splitting the moment of inertia was rejected.

It was noted that when a post hoc test (Tukey) was used to check the mean difference in the overall $F$ test as in the case of Burton and Turvey (1990), only one out of 
Table 3

Mean Perception of Whole and Partial Lengths by Wielding the Rod in Experiment 3

\begin{tabular}{|c|c|c|c|c|c|}
\hline $\begin{array}{l}\text { Attachment } \\
\text { Conditions }\end{array}$ & $\begin{array}{l}\text { Static Torque } \\
\mathbf{N}_{\mathbf{s}}(\mathrm{N} \cdot \mathrm{m})\end{array}$ & $\begin{array}{c}\text { Moment of } \\
\text { Inertia } I \\
\left(\mathrm{~kg} \cdot \mathrm{m}^{2}\right)\end{array}$ & $\begin{array}{c}\text { Perceived } \\
\text { Forward } \\
\text { Length }(\mathrm{m})\end{array}$ & $\begin{array}{c}\text { Perceived } \\
\text { Whole } \\
\text { Length }(\mathrm{m})\end{array}$ & $\begin{array}{c}\text { Perceived } \\
\text { Length } \\
\text { Ratio } Q^{\prime} \\
\end{array}$ \\
\hline \multicolumn{6}{|c|}{$50-\mathrm{cm}$ rod } \\
\hline No attachment & 0.000 & 0.00096 & 0.0073 & 0.0154 & 2.07 \\
\hline Front & 0.041 & 0.00123 & 0.0120 & 0.0185 & 1.60 \\
\hline Front end & 0.154 & 0.00479 & 0.0155 & 0.0224 & 1.37 \\
\hline Rear & -0.041 & 0.00123 & 0.0055 & 0.0963 & 3.44 \\
\hline Rear end & -0.154 & 0.00479 & 0.0055 & 0.0209 & 4.22 \\
\hline \multicolumn{6}{|c|}{$80-\mathrm{cm}$ rod } \\
\hline No attachment & 0.000 & 0.00362 & 0.0088 & 0.0190 & 2.13 \\
\hline Front & 0.039 & 0.00386 & 0.0127 & 0.0228 & 1.55 \\
\hline Front end & 0.249 & 0.01361 & 0.0211 & 0.0292 & 1.45 \\
\hline Rear & -0.039 & 0.00386 & 0.0082 & 0.0235 & 3.18 \\
\hline Rear end & -0.249 & 0.01361 & 0.0061 & 0.0306 & 4.47 \\
\hline
\end{tabular}

four comparisons was significant. When the mass was added to the forward length, reported forward length was longer and the variance in this configuration was larger. In an overall $F$ test, the variance in all configurations is included in the error term. Moreover, to compensate for the large number of unnecessary comparisons, the adjusted critical value for each comparison is reduced tremendously. As a result, it is very difficult to show any significant difference. This could be the main reason why no difference was found by either Solomon et al. (1989) or Burton and Turvey (1991).

Calculated forward length (perceived whole length $/ Q^{\prime}$ ), when regressed on perceived forward length (Figure 8), showed a high correlation $\left(R^{2}=.97\right)$. This indicated that forward length can be perceived in relation to the perceived whole length and the perceived length ratio, $Q^{\prime}$. To check what dynamic variables specify $Q^{\prime}$, the perceived forward length, and the perceived whole length, these three length estimates were regressed on $\mathbf{N}_{\mathrm{s}}$ and $I$ (Figures 9 and 10 ). When regressed on $\mathbf{N}_{\mathrm{s}}, R^{2}$ was close to .8 only for the perceived forward length and $Q^{\prime}$. When

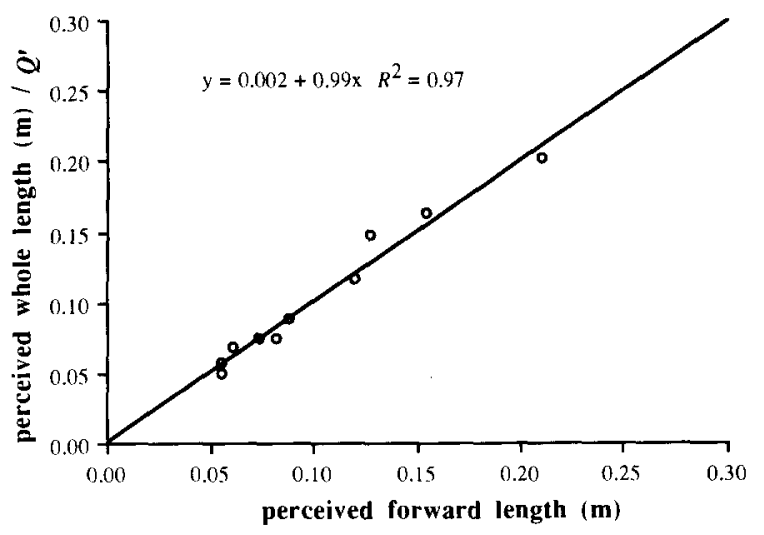

Figure 8 . The perceived forward length can be obtained by dividing the perceived whole length by the perceived length ratio, $Q^{\prime}(\mathbf{E x}-$ periment 3). regressed on $I, R^{2}$ was greater than .8 only for the perceived whole length. These results suggest that the whole length is specified by $I$, whereas partial length and $Q^{\prime}$ are specified by $\mathbf{N}_{s}$. This is exactly as expected, because $I$ is not sensitive to the differential lengths of the forward and backward segments, whereas $\mathbf{N}_{s}$ is.

Pagano, Kinsella-Shaw, Cassidy, and Turvey (1994) showed that the location of grip is also revealed by an off-diagonal component of the inertia tensor. Perhaps both the static force structures (in terms of static torque and the ratio of $\mathbf{D} / \mathbf{U}$ ) and the off-diagonal component of inertia tensor can specify the grip location. Yet because of the illusory shrinking of the perceived forward length as shown, the specification of grip location should not be very accurate.

\section{GENERAL DISCUSSION}

\section{Perception of Partial Length}

Three experiments were conducted that were similar to previous studies on perception of partial-rod length (Solomon et al. 1989; Burton \& Turvey, 1990), but with slight modifications. In Experiment 1, instead of using mass attachment to simulate different rod lengths, the backward length itself was actually varied. In all the experiments, the distribution of mass of the forward length was held constant. When a mass was attached to the forward length (Experiment 3 ), data from such trials were excluded from the analysis. Such trials were unrelated to the testing of the hypothesis that perceived forward length is affected by the distribution of mass of the backward length. It was also found that if such trials were included and a post hoc test was used for mean comparisons, the error term would be very large, while the critical value for each comparison would be reduced tremendously, rendering significance difficult to reach. This is speculated to be the main reason why the effect of the distribution of mass of the backward length on perceived forward length was not found in the previous studies. The results of the present research showed that when a cylindrical 


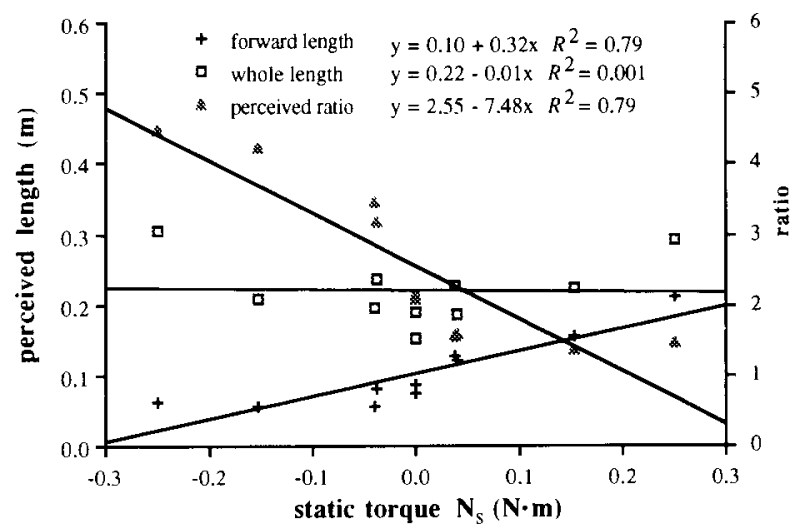

Figure 9. The static torque, $N_{\mathrm{s}}$, specifies forward length and the perceived length ratio, $Q^{\prime}$, but not the whole length (Experiment 3 ).

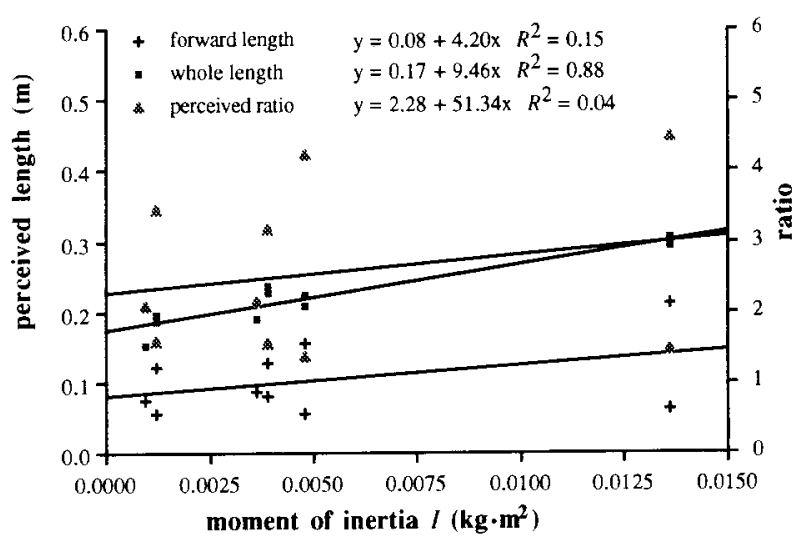

Figure 10. The moment of inertia, $I$, specifies the whole length, but not the forward length or the perceived length ratio, $Q^{\prime}(\mathbf{E x}$ periment 3).

rod is gripped at a position intermediate between its two ends, irrespective of whether it is held stationary or wielded, the perceived forward length is affected by the distribution of mass of the backward length. This shows that forward length is not perceived by the attentional splitting of a mechanical property of the rod (the first moment or the moment of inertia).

Furthermore, the results showed that it is the resultant force structure acting on the hand that specifies the forward length of a rod. When the distribution of mass of the forward length is greater than that of the backward length, the resultant force structure is similar to that of holding a rod at its rear end. Thus, the perceived forward length is long. When the distribution of mass of the backward length is made greater by lengthening it or by attaching a mass to the backward length, the resultant force structure is similar to that of holding a rod at the front end, so the perceived forward length is short.

In comparing results in the three experiments, variation of weight was found to reduce the effect of static torque on the perceived forward length. When weight re- mained unchanged, as in Experiment 2, static torque explained $99 \%$ of the variance in the perceived forward length. When variation of weight was large, as in Experiment 3 , static torque only explained $79 \%$ of the variance of the perceived forward length.

\section{The Notion of an Invariant}

Though perception of forward length is shown to be illusory, it is still useful to examine how the judgment is made when a subject is asked to make partial-length judgment of a rod held stationary or wielded. Perception has been shown to be a result of the detection of an invariant (something that is unchanged through the covariation of a number of variables; Gibson, 1979; Turvey \& Carello, 1986). Can the results of partial perception of rod length in this research be explained in terms of invariant detection?

Gibson (1979) described four kinds of invariants which can be grouped into two categories. There seem to be three different emphases in defining invariants. The first emphasis is on the perceivable structure in the optic array. In this regard, Gibson $(1979$, p. 311$)$ defined an invariant as "a common structure" in "the sampling of the ambient optic array," or as "certain non-disturbances of optical structure." An example of the latter would be the preserved structure of a ball while it is rolling. The second emphasis is on the relationship between variables. Gibson (1979, p. 301) illustrated this by the constant " intensity ratio" under changing illumination, and by the constant "horizon-ratios" with changing points of observation. The invariant shows the underlying relationship of the variables. It is a function of the variables. Later work has shown many such examples; perception of time-tocontact, for instance, is a ratio of the size of a retinal image of an object to the rate of change of the size (Wagner, 1982). Moreover, the function may contain a number of variables. Bingham, Schmidt, and Rosenblum (1989) showed that the invariant to specify throwability of a stone depends on the size and weight. The third emphasis appeared in recent research on perception of rod length, in which invariants are regarded as the properties of the rod: the first moment in the case of holding the rod stationary and the moment of inertia in the case of wielding it (Burton \& Turvey, 1991; Carello et al., 1992; Solomon \& Turvey, 1988; Solomon et al., 1989). The property can even be split up by attention. In this regard, the distal stimulus is emphasized. Of these three different emphases of invariants, the results of the present research seem to be most compatible with the notion of invariants as functions.

In this research, it was found that static torque may specify whole length, forward length, or perceived length ratio depending on the functions $f, h$, and $k$ in Equations 1 to 3 that map the same variable, static torque, into different perceived properties. Moreover, a number of variables may enter into the functions yielding length judgments; in the case of holding a rod stationary, such variables are static torque and weight; when the rod is wielded, the variables are static torque, weight, inertial torque, and angular acceleration in the haptic array. 
Although it is beyond the scope of this research to give a more detailed description of these functions, their role is certain: The functions combine a limited number of variables in various ways to form a large number of perceptions.

Moreover, the results of this research support multiple specifications: There is more than one function of variables that specifies each perceived property (Michaels \& Oudejans, 1992). Each function of variables may contain a number of unspecified coefficients and constants. A function of $\left|\mathbf{N}_{s}\right|$ and $\mathbf{W}$ in Equation 1 may look like $\left(a \mathbf{N}_{s}^{b}\right.$ $\left.+c \mathbf{W}^{d}+e \mathbf{N}_{\mathrm{s}}^{r} \mathbf{W}^{u}\right)$, where $a, b, c, d, e, r$, and $u$ are coefficients and constants. In solving simultaneous equations, it is well known that in order to produce a unique solution, the number of independent equations must be equal to the number of unknowns. When the number of independent equations is fewer than the number of unknowns, more than one solution is possible. The number of possible solutions can only be reduced by having more independent equations. In this research, perceived forward length is found to be specified by static torque and also by perceived whole length divided by perceived length ratio, $Q^{\prime}$. It is speculated that such use of multiple specifications reduces the number of possible solutions. In haptic research, it is a commonplace phenomenon that subjects cannot give a specific estimation. Many alternative estimations appear likely. Although order of rod length is preserved in subjects' responses, the exact magnitude is seldom produced. Such variability and inaccuracy must be taken into consideration if such haptic judgment of rod length is to be regarded as perception at all. This can be explained very well if multiple functions are allowed. On the other hand, if perception is regarded as the result of isomorphic mapping between unique invariants and perceived properties, such variation and inaccuracy should never occur.

\section{Attention}

G. Bingham (personal communication, March 1993) raised an important question concerning the ontological status of these functions: Where should the functions be understood to reside? Are these functions neural things, task-determined things, or physical things? Although a clear description of the ontological status of these functions is beyond the scope of this research, the results suggested that functions may be a combination of all these things. Functions may involve physical properties such as the moment of inertia that specifies the relationship between inertial torque $\mathbf{N}_{\mathrm{i}}$ and angular acceleration $\dot{\omega}$ in the haptic array. Functions may be task specific, so that holding the rod stationary will produce different variables and functions than would wielding the rod up and down. Functions should also involve neural elements that are part and parcel of any perceptual modality. Certainly, the intentional and attentional conditions of a person affect the functions. This effect may be considered to be achieved through the changing of the neural organization. Such consideration is especially important when different segments of the rod can be perceived without any movement. When there is movement, one may argue that functions are taskdetermined things. When there is no movement, forces applied to the hand, and thus the muscular reactions, are held constant and can be completely determined by the laws of statics. Perception of different properties can only be achieved through a change in neural organization.

Moreover, the study of covert attention (Inhoff, Pollatsek, Posner, \& Rayner, 1989; Posner, 1988; Posner, Walker, Friedrich, \& Rafal, 1987) shows that different sources of visual information can be attuned to, even without the shift of the eye. Covert attention is certainly relevant in the perception of different parts of a rod held stationary. Burton and Turvey (1991) tried to explain this selectivity with covert partitioning based on the study of overlapping displays (Neisser \& Becklen, 1975). Such partitioning was thought to be the splitting of the first moment. With invariants taken as functions, attentional shift can be regarded as a change of the functions. Such functions, which are dependent on the physical properties of the perceived object and the exploratory movement of the perceiver, are also determined by the organization of the neural substrate. The organized network in the brain, together with the input and output modalities, forms an expert system specific to a certain perceptual task such as walking, talking, or drawing. Such speculation is compatible with the notion of self-assembly and smart mechanisms in the organization of human behavior (Kugler \& Turvey, 1987; Runeson, 1977). It also agrees with Posner's proposal (Posner, 1988; Posner \& Cohen, 1984; Posner, Cohen, \& Rafal, 1982) that attention involves the orchestration of multiple elementary operations, each of which is localized to a specific brain area. In carrying out a new task, the brain has to disengage from a previous organization and engage in a new one. The parietal lobe, the midbrain, and the frontal lobe have been identified as the centers for disengagement, attentional shift, and maintenance of attention. Attention, therefore, alters the neural organization that forms expert systems to process the same stimulation input in different ways. Each of the organizations would be compatible with one or more of the functions such as $f, g$, and $h$ in Equations 1 to 3 .

\section{REFERENCES}

Bingham, G. P., Schmidt, R. C., \& Rosenblum, L. D. (1989). Hefting for a maximum distance throw: A smart perceptual mechanism. Journal of Experimental Psychology: Human Perception \& Performance, 15, 507-529.

Burton, G., \& Turvey, M. T. (1990). Perceiving the lengths of rods that are held but not wielded. Ecological Psychology, 2, 295-324.

BurTon, G., \& TuRveY, M. T. (1991). Attentionally splitting the mass distribution of hand-held rods. Perception \& Psychophysics, 50, 129-140.

Carello, C., Fitzpatrick, P., Domaniewicz, I., Chan, T. C., \& TURVEY, M. T. (1992). Effortful touch with minimal movement. Journal of Experimental Psychology: Human Perception \& Performance, 18, 290-302.

Chan, T. C., \& Turvey, M. T. (1991). Perceiving the vertical distances of surfaces by means of a hand-held probe. Journal of Experimental Psychology: Human Perception \& Performance, 17, 347-358.

GiBson, J. J. (1979). The ecological approach to visual perception. Boston: Houghton Mifflin. 
Goldstein, H. (1980). Classical mechanics. Reading, MA: AddisonWesley.

HoIsington, L. B. (1920). On the non-visual perception of the length of lifted rods. American Journal of Psychology, 31, 144-146.

InhoFf, A. W., Pollatsek, A., Posner, M. I., \& Rayner, K. (1989). Covert attention and eye movement during reading. Quarterly Journal of Experimental Psychology: Human Experimental Psychology, 41, 63-89.

KEPPEL, G. (1991). Design and analysis: A researcher's handbook. Englewood Cliffs, NJ: Prentice-Hall.

Kugler, P. N., \& TURVEY, M. T. (1987). Information, natural Law, and the self-assembly of rhythmic movement. Hillsdale, $\mathrm{NJ}$ : Erlbaum.

Michaels, C. F., \& Oudejans, R. R. D. (1992). The optics and actions of catching fly balls: Zeroing out optical acceleration. Ecological Psychology, 4, 199-222.

NeIsser, U., \& BECKLEN, R. (1975). Selective looking: Attending to visually specified events. Cognitive Psychology, 7, 480-494.

Pagano, C., Kinsella-Shaw, J. M., Cassidy, P. E., \& Turvey, M. T. (1994). Role of the inertia tensor in haptically perceiving where an object is grasped. Journal of Experimental Psychology: Human Perception \& Performance, 20, 1-10.

POSNER, M. I. (1988). Structures and functions of selective attention. In T. Boll \& D. K. Bryant (Eds.), Clinical neuropsychology and brain function: Research, assessment and practice (pp. 173-202). Washington, DC: American Psychological Association.

Posner, M. I., \& CoheN, Y. (1984). Components of attention. In H. Bouma \& D. Bowhuis (Eds.), Attention and performance X (pp. 5566). Hillsdale, NJ: Erlbaum.

Posner, M. I., Cohen, Y., \& Rafal, R. D. (1982). Neural systems control of spatial orienting. Philosophical Transactions of the Royal Society of London: Series B, 298, 187-198.
Posner, M. I., Walker, J. A., Friedrich, F. J., \& Rafal, R. D. (1987). How do the parietal lobes direct covert attention? Neuropsychologia, 25, 135-145.

RUNESON, S. (1977). On the possibility of "smart" perceptual mechanisms. Scandinavian Journal of Psychology, 18, 172-179.

SOLOMON, H. Y., \& TURVEY, M. T. (1988). Haptically perceiving the distances reachable with hand-held objects. Journal of Experimental Psychology: Human Perception \& Performance, 14, 404-427.

Solomon, H. Y., Turvey, M. T., \& Burton, G. (1989). Perceiving extents of rods by wielding: Haptic diagonalization and decomposition of the inertia tensor. Journal of Experimental Psychology: $\mathbf{H u}$ man Perception \& Performance, 15, 58-68.

Turvey, M. T., \& CARELlo, C. (1986). The ecological approach to perceiving-acting: A pictorial essay. Acta Psychologica, 63, 133-155.

WAGNER, H. (1982). Flow-field variables trigger landing in flies. $\mathrm{Na}$ ture, 297, 147-148.

\section{NOTES}

1. Because $\mathbf{W}=m \mathbf{g}$ and $\mathbf{g}=9.81 \mathrm{~m} / \mathrm{sec}^{2}, 1 \mathrm{~kg}$ wt equals 9.81 newtons.

2. In this paper, the mass of the hand is neglected, although some authors, such as Kugler and Turvey (1987), included it in their calculation. Exclusion of the mass of the hand does not affect the results. Firstly, the moment of inertia is a linear combination of its component parts and the moment of inertia of the hand is always there in all situations. This is also the case with weight and static torque. Furthermore, Solomon and Turvey (1988) also said: "[since] the hand-as-disk's axial moment of inertia is small relative to the rod's, the axial-diametral moment of inertia difference may be negligible" (p. 419).

APPENDIX

The Dynamic Variables and Constants Used in This Paper

\begin{tabular}{ll}
\hline \multicolumn{1}{c}{ Variables } & Units \\
$\begin{array}{l}\text { Moment arm }(\mathbf{r}): \text { perpendicular distance from the center of mass to the vertical } \\
\text { axis through the pivot point }\end{array}$ & meter $(\mathrm{m})$
\end{tabular}

axis through the pivot point

Acceleration due to a rectilinear force (a): force $=m \mathbf{a}$

$\mathrm{m} / \mathrm{sec}^{2}$

Acceleration due to gravity $(\mathrm{g}): \mathbf{g}=9.81 \mathrm{~m} / \mathrm{sec}^{2}$

$\mathrm{m} / \mathrm{sec}^{2}$

Objective length ratio $(Q)$ : the actual ratio of the whole length to the forward length of a rod

Perceived length ratio $\left(Q^{\prime}\right)$ : the perceived ratio of the whole length to the forward length of a rod

Angular acceleration $(\dot{\omega})$ : the rate of change of angular velocity, where angular velocity $\omega$ is the rate of change of angular displacement. Angular displacement is measured in radians; there are $2 \pi$ radians in a circle.

Mass $(m)$ : amount of matter

First moment of mass $(\mathbf{M})$ : distribution of mass with reference to an axis. $\mathbf{M}=m \mathbf{r}$

Moment of inertia $(I)$ : inertia to rotation. For a unit mass $m$ with distance $r$ from the axis of rotation, $I=m r^{2}$. For a homogeneous cylindrical rod of mass $m$, length $L$, and radius $a$, the moment of inertia about an axis through the center of mass perpendicular to the rod length is:

$$
I=\frac{m}{12}\left(3 a^{2}+L^{2}\right)
$$

Weight $(\mathbf{W})$ : force produced by a mass under gravity. $\mathbf{W}=m \mathbf{g}$

Static torque $\left(\mathbf{N}_{s}\right)$ : turning tendency due to static forces such as a weight act-

newton $(\mathrm{N})$

newton-meter $(\mathrm{N} \cdot \mathrm{m})$

ing at a distance from a pivot point. $\mathbf{N}_{\mathrm{s}}=\mathbf{r} \times \mathbf{m g}$

Inertial torque $\left(\mathbf{N}_{\mathrm{i}}\right)$ : resistance to rotational acceleration due to inertia. $\mathbf{N}_{\mathbf{i}}=I \dot{\omega}$

\section{kilogram (kg) \\ kilogram-meter $(\mathrm{kg} \cdot \mathrm{m})$}

kilogram-meter squared $\left(\mathrm{kg} \cdot \mathrm{m}^{2}\right)$ 